\title{
DiÁLOGO ENTRE TEXTOS E IMÁGENES: ANÁLISIS MULTIMODAL DE TEXTOS ESCOLARES DESDE UNA PERSPECTIVA INTERTEXTUAL
}

\section{(A dialogue between texts and immages: a multimodal analysis} of school texts from an intertextual perpective)

\author{
Teresa Oteíza \\ (Universidad Austral de Chile)
}

\begin{abstract}
Desde el momento en que una cultura ha tomado la decisión de incorporar un determinado material en sus procesos comunicativos, ese material se convierte en parte de los recursos culturales y semióticos de esa cultura y queda disponible para que nosotros construyamos signos.

(G. Kress y T. van Leeuwen, 2001)
\end{abstract}

\section{Introducción}

El presente análisis de textos escolares de historia chilenos examina cómo se construyen algunos puntos de vista ideológicos a través de las imágenes y cómo éstos se relacionan con el texto escrito. Está bien documentado que en los textos escolares, el metadiscurso evaluativo como las indicaciones de juicios explícitos, se presentan de una manera poco accesible para los estudiantes (Coffin 2002, 2006; Crismore 1984; Schleppegrell, Achugar y Oteíza 2004; Achugar y Schleppegrell 2005; Oteíza 2003, 2006, en prensa; Oteíza y Pinto 2008, entre otros). Sin embargo, las imágenes son un recurso importante que tiene el potencial de aportar con estos significados al discurso pedagógico de historia y, por lo mismo, colaborar a construir una explicación histórica. A diferencia de otros textos escolares del área de la ciencia, los textos escolares de historia muestran una menor integración entre los elementos visuales y la información adicional. (Baldry 1999; Guo 2004). Recogiendo este planteamiento teórico y metodológico, intento presentar cómo las imágenes de los textos escolares de historia chilenos dialogan con el texto lingüístico generando, por ejemplo, significados contradictorios, silencios (Trouillot 1995) y transformaciones que tienen el potencial de influir ideológicamente a los estudiantes. Me sumo a la visión de Kristeva (1986) y Lemke (1995) 
en el sentido de que la intertextualidad (Bakhtin 1981), y en este caso la multimodalidad inter-textos, no se refiere exclusivamente a una relación entre formas lingüísticas o individuos, sino que alude a una relación entre puntos de vista. Intentaré mostrar el desarrollo en el tiempo de la inclusión de algunas imágenes y las variaciones en el diálogo que éstas entablan con el material lingüístico desde una perspectiva intertextual e intratextual. Este trabajo se centrará en los siguientes aspectos: (1) Representación de la violencia, (2) Representación de Augusto Pinochet, y (3) Representación del palacio presidencial de "La Moneda".

El análisis multimodal responde a la conciencia de que los 'textos escritos' están siempre en diálogo con otras formas semióticas. En este sentido, los textos siempre son multimodales (Kress 1996). Un texto multimodal es entendido como el resultado de una acción social, como cualquier instancia de comunicación en cualquier modo o combinación de modos (Kress 2003), esto se debe a que las imágenes visuales son producidas, distribuidas y consumidas cultural y socialmente (Lister y Wells, 2001) y, por lo mismo, no es posible analizar las imágenes separadas del proceso social en las que ellas existen. Asimismo, este análisis debe tomar en consideración que cada modo tiene inherentemente un potencial de representación que difiere del resto de los modos semióticos lo que, en parte, está dado por su materialidad. Consecuentemente, cada modo semiótico debiera evaluarse de manera diferente de acuerdo al contexto en el que es utilizado sin dejar de considerar el género al que pertenece.

Los textos multimodales analizados combinan dos tipos de lógicas diferentes: el escrito la lógica del tiempo (linealidad) y las fotografías la lógica del espacio (Kress y van Leeuwen 1996; Kress 2003). Esto será relevante de tener en cuenta para el análisis de los posibles "recorridos de lectura" que ofrecen los textos multimodales tanto inter-semióticos como intra-semióticos (Kress y van Leeuwen 1996; Kress 2003), así como las posibilidades de interpretación de los mismos (relación productor-lector en el ámbito educacional). Las imágenes no son siempre "transparentes" señalan Kress y van Leeuwen (1996), si bien tendemos a pensar que las imágenes son fáciles de interpretar y de que su significado es evidente u obvio para el observador; sin embargo, si consideramos que las imágenes visuales son construidas culturalmente por una comunidad, resulta necesario aprender a leer las imágenes (Kress \& van Leeuwen, 1996). Necesitamos saber cómo usar las herramientas que nos permiten ser "letrados o 
alfabetizados" en esta lectura y adquirir un significado más rico de las imágenes. El referirnos a una alfabetización de lo visual nos plantea un problema teórico nuevo ya que habría que revisar cómo nos acercamos a un mundo que cada vez le da más prominencia a lo visual (Kress 2003).

\section{Una gramática de las imágenes}

Kress \& van Leeuwen (1996) proponen extender las herramientas sistemáticas que provee una gramática sistémico funcional al análisis del sonido y de las imágenes, argumentado que estos modos semióticos también poseen una estructura o una gramática. De esta forma, las tres áreas de representación constituyen una extensión de las tres metafunciones o macro significados propuestos por Halliday (1994) para el análisis del lenguaje escrito: ideacional, textual e interpersonal. Estas metafunciones son entendidas como tres grandes áreas de producción de significado en general. La metafunción ideacional o representacional hace alusión a la representación de los eventos y participantes, la metafunción textual o composicional se refiere a la estructura o composición de las imágenes y la metafunción interpersonal alude a la relación entre imagen y observador. ${ }^{6}$

Los textos escolares de historia analizados corresponden aquellos textos Pre-Reforma Educacional de 1999 (Octavo año básico y cuarto año de secundaria) y Post-Reforma Educacional de 1999 (sexto año básico y segundo año de secundaria). En estos niveles se trabaja la historia de Chile en el sistema educacional. El periodo de la historia que he analizado comprende desde 1970 hasta el presente (gobierno de S. Allende 19701973; golpe militar de 1973; dictadura militar de A. Pinochet, 1973-1989 y gobiernos de la transición democrática- Aylwin, Frei y Lagos). Los textos escolares corresponden a los publicados entre 1993 y 2006. Siete de los diez textos analizados han ganado la licitación del Ministerio de Educación para ser usados en todos los colegios públicos (subvencionados/ municipalizados) del país.

Los textos escolares analizados presentan una clara preferencia por la inclusión de fotografías (más del $90 \%$ de las imágenes son fotos). La producción semiótica de los textos escolares está especialmente orientada a

\footnotetext{
${ }^{6}$ Por restricciones de espacio no puedo explayarme en esta sección de metodología. Para una explicación detallada de cada categoría, ver Kress \& van Leeuwen 1996, 2001.
} 
la interpretación de los estudiantes y menos a la producción por parte de ellos. En este sentido, el contexto de interacción con las imágenes es clave ya que tendemos a mirar las imágenes con expectativas específicas. ¿Qué le agrega, por ejemplo el ambiente pedagógico a la observación de las imágenes en un texto de historia?

\section{Análisis}

Las fotografías tienen la particularidad de tener un carácter de 'evidencia' y representan una 'orientación naturalista del código'. (Kress \& van Leeuwen 1996; Pang Kah Meng 2004). En los textos escolares se produce una recontextualización de las fotografías ya que éstas no fueron tomadas para ser presentadas este medio ni con fines pedagógicos. Asimismo, es importante tener en cuenta que las imágenes suelen repetirse de texto a texto debido, en parte, a la disponibilidad de los bancos de imágenes de las editoriales que producen los textos escolares.

\subsection{Representación de la violencia}

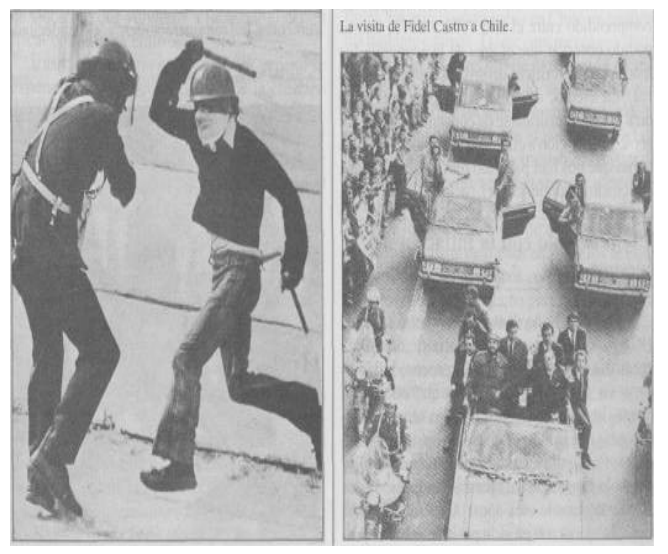

Imagen 1 e 2.

Imagen 1: "Violencia en las calles" (Salesiana cuarto año de secundaria 1993, Pre-Reforma Educacional). Desde un punto de vista composicional, esta fotografía representa el conocimiento "dado" en relación con la imagen que se encuentra inmediatamente junto a ella y que muestra la visita de Fidel Castro a Chile en 1972. Se establece una conexión visual entre la 
violencia y las figuras de F. Castro y S. Allende. Si tomamos en cuenta la perspectiva representacional (eventos y participantes), estamos frente a una narrativa en la que el policía es presentado como víctima (Meta) y el joven como Agente y victimario. Desde el significado interpersonal corresponde a una oferta, dado que no se establece un contacto visual con el receptor, la toma es de larga distancia, y la fotografía es en blanco y negro (modalidad alta/ alta credibilidad). ${ }^{7}$

Imagen 2: "Visita de Fidel Castro a Chile". Esta fotografía de ubica a la derecha y parte inferior de la página, lo que la asocia con lo real y la información nueva (composicional). Corresponde a una narrativa (representacional). La toma es de muy larga distancia y, por lo mismo, se pierde el contacto con el observador. Se precisa de un mínimo de conocimiento de la vida política para reconocer a las figuras de Fidel y de Allende (interpersonal). Las imágenes 1 y 2 refuerzan los significados expresados en el texto escrito que se refiere al clima de extrema violencia que 'forzó' a las Fuerzas Armadas y de Orden a 'intervenir' con un golpe de Estado en 1973. Es importante puntualizar que estas imágenes junto a las de dirigentes de la extrema izquierda chilena ya no están presentes en los textos escolares posteriores a la Reforma Educacional en los que se desea promover la reconciliación entre los chilenos y privilegiar los consensos por sobre las polarizaciones del pasado reciente.
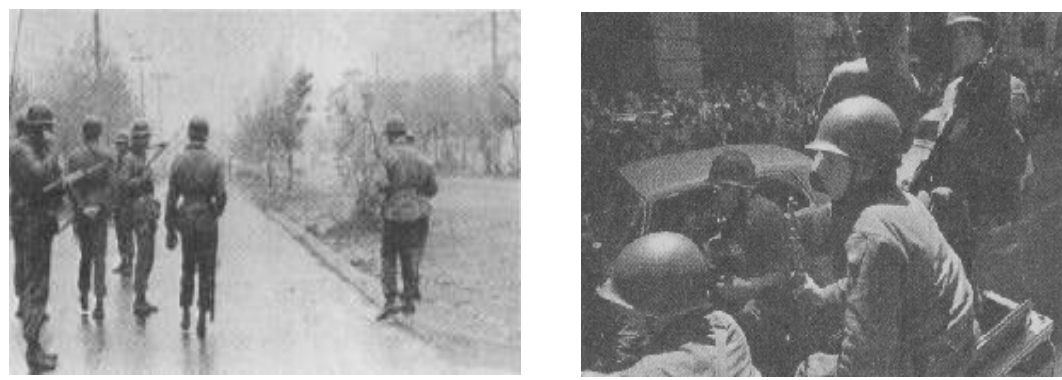

Imagen 3 e 4.

Imagen 3: "Vigilancia policial y militar durante las protestas de los últimos años del gobierno militar (Arrayán sexto año 1999, Post-

\footnotetext{
7 Presentaré un análisis muy reducido de cada imagen dadas las restricciones de espacio. Entre paréntesis he incorporado la categoría de análisis al que corresponde.
} 
Reforma Educacional). Esta fotografía que se encuentra en el centro derecho de la página con una prominencia mediana, en parte porque es una imagen pequeña (composicional), es una narrativa que presenta a los militares vigilando las calles de Santiago. La violencia no se ve (se divisan manifestantes al fondo de la imagen, casi imperceptibles, lo que establece una diferencia en relación al texto de 1993 desde título de la foto: "violencia" vs. "vigilancia" (representacional). La toma es de larga distancia, lo que evoca una distancia social y refuerza la percepción de objetividad que crea el blanco y negro. Los militares dan la espalda (interpersonal).

Imagen 4: "Militares" (McGrawHill sexto año 2000 y Marenostrum 2005-2006, Post-Reforma Educacional). Esta imagen se ubica en el área centro-izquierda de la página, con una mediana prominencia o en los márgenes en ediciones posteriores (composicional). Es a su vez una narrativa (más evidente por los vectores formados por las armas y brazos de los militares) y corresponde a una oferta mediana que no invita a que el observador se involucre. Los soldados no establecen una conexión visual con el observador. El color medianamente saturado produce una efecto de realidad (fotografía reciente). Esta representación es diferente al período de la Unidad Popular que es representado en blanco y negro en el manual. El texto escrito de la página se refiere a la falta de libertad política y constitucional a la vez que a las "muchas" violaciones a los derechos humanos que ocurrieron durante la dictadura de Pinochet. El texto escrito es más explícito, claro y enfático en relación a la violencia del "gobierno militar" que la imagen.

\subsection{Representación de Augusto Pinochet}

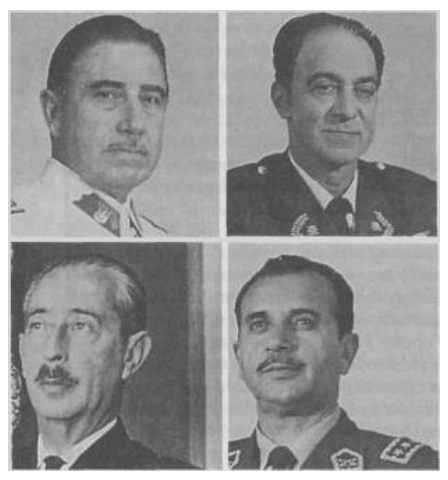

Imagen 5. 
Imagen 5: Junta Militar (primeros años de la dictadura) (Textos Pre y Post-Reforma Educacional).

Estas fotografías que corresponden a los cuatro militares que formaron la Junta Militar en 1973 y que gobernaron en los primeros años de la dictadura, aparecen en 8 de los 10 textos analizados. Esta imagen se ubica en variadas posiciones de la página en distintos textos escolares, todos con una prominencia mediana. Desde un punto de vista representacional es una imagen conceptual ya que sus participantes son parte de un proceso Relacional-identificativo: "Nosotros somos la Junta Militar"/ "Estos son los integrantes de la Junta Militar". Pinochet mira directamente al observador estableciendo un contacto visual que es casi una demanda. Pinochet se ve serio, seguro, con confianza en sí mismo, es representado como un líder.

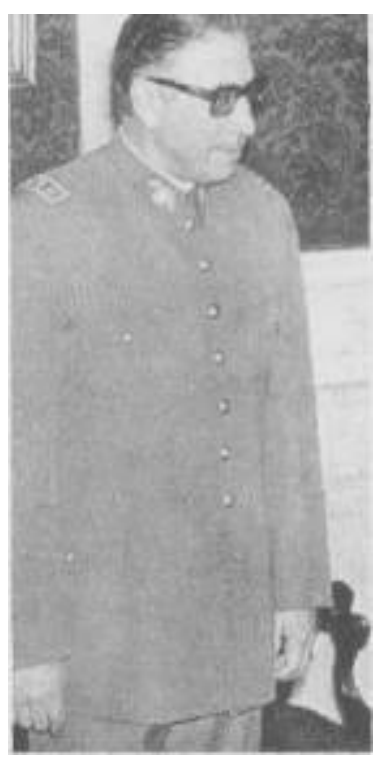

Imagen 6.

Imagen 6: Augusto Pinochet (primeros años) (Arrayan sexto año (1999). Post-Reforma Educacional). Esta imagen se encuentra en el centroizquierdo de la página con una mediana prominencia. Se ubica en una sección de "actividades" en la que se solicita a los estudiantes comparar las constituciones de 1925 y 1980 en relación al papel asignado a la Fuerzas Armadas y determinar si el golpe de estado fue constitucional. Corresponde 
a una imagen conceptual y a una oferta. Pinochet no establece un contacto visual con el observador (lentes oscuros, ángulo oblicuo de la toma). En esta imagen se aprecia a un Pinochet militar, distante, confiado y casi esbozando una sonrisa.

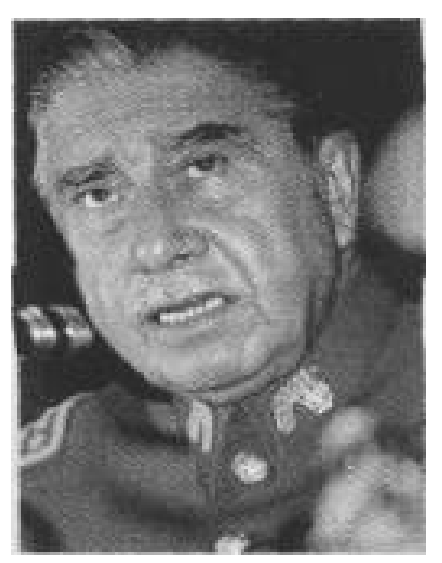

Imagen 7.

Imagen 7: Augusto Pinochet (mediados de los ochenta) McGrawHill sexto año (2001) Post-Reforma Educacional. Esta es una imagen prominente y que se ubica en la parte derecha superior de la página. Esta fotografía es en parte narrativa y en parte conceptual ya que es evidente que Pinochet está dando un discurso (micrófono). Se ve serio, concentrado, menos confiado que en fotografías previas. Si bien Pinochet mira hacia fuera de la imagen, establece un contacto con el observador. Dado el color

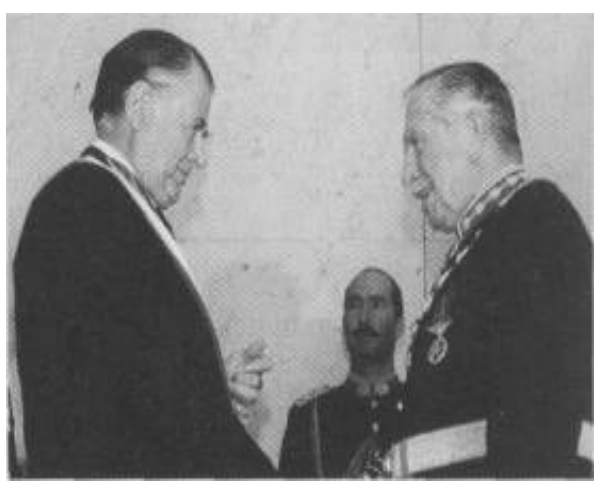

Imagen 8. 


\section{Imagen 8: Patricio Aylwin y Augusto Pinochet, 1990}

Cambio de mando. (Post-Reforma Educacional). Esta es una fotografía simbólica que se repite en los 5 textos de estudio más recientes (19992006). Aylwin fue el primer presidente democrático después de 17 años de dictadura. En el texto producido para los años 2005-2006 constituye la imagen de fondo de toda la página del comienzo de la unidad sobre "transición democrática".

Aylwin y Pinochet se dan la mano y se miran. Aylwin esboza una sonrisa, Pinochet claramente sonríe. Esta imagen de Pinochet contrasta con el resto de las imágenes en las que es representado desde el año 1993 en los textos de estudio. En esta imagen Pinochet aparece como un hombre mayor, noble y respetable que ha terminado su periodo (representado como si hubiera sido un presidente) y le da la bienvenida al nuevo presidente como en una continuación de un acto constitucional.

\subsection{Representación del palacio presidencial de "La Moneda".}

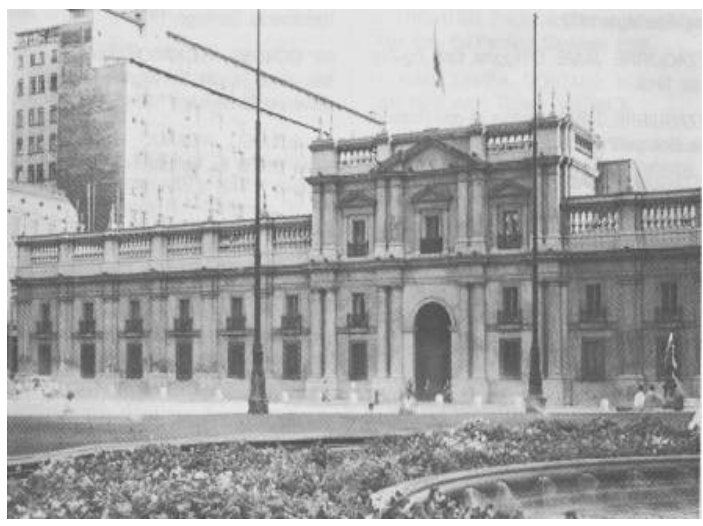

Imagen 9.

Imagen 9: Santillana (cuarto año de secundaria 1994). (Pre-Reforma Educacional). Esta fotografía, sin título, se ubica en el centro de la página, es prominente dado su tamaño (un tercio de la página) y porque constituye la única imagen. Corresponde a una imagen conceptual. En el primer plano del Palacio de La Moneda se aprecia un jardín con césped y flores que evoca un sentimiento de tranquilidad. Desde un punto de vista interpersonal genera una involucración mediana y una distancia social con el observador. 
En el texto escrito se "reporta" desde una fuerte monoglosia que ocurrió un golpe militar el 11 de septiembre de 1973 y que se estableció una Junta Militar (oraciones afirmativas, uso de tercera persona impersonal con "se").

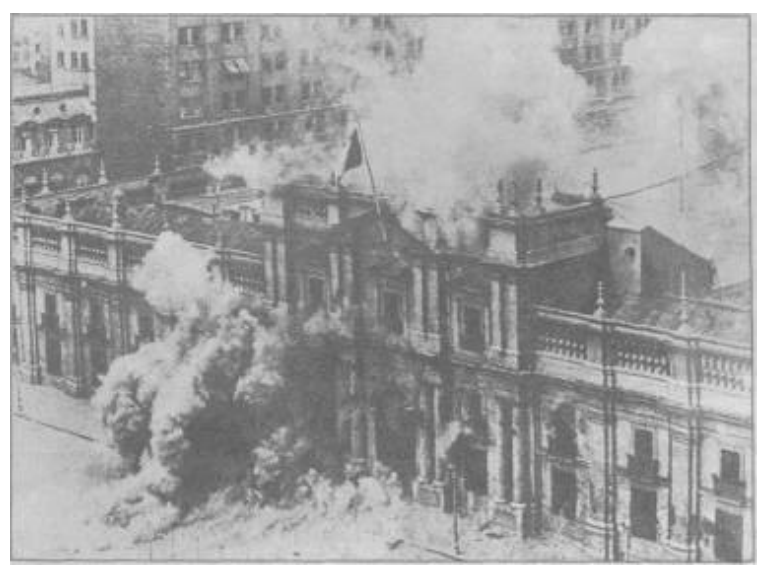

Imagen 10.

Imagen 10: La Moneda siendo bombardeada el 11 de septiembre de 1973. Post-reforma Educacional. Esta es una imagen simbólica que fue publicada en numerosos diarios y que circuló alrededor del mundo el día después del bombardeo. Aparece en todos los textos menos uno en diferentes posiciones y tamaños. Las fotografías son un poco más pequeñas en los textos escolares recientemente publicados. En esta oportunidad estamos frente a una narrativa ya que La Moneda está siendo bombardeada desde el aire. Se produce un contraste con fotografía previa: flores vs. humo/ imagen conceptual vs. imagen narrativa. En relación al mensaje verbal, con algunas diferencias, todos los textos hacen referencia al ambiente de crisis o caos político y económico que vivía el país durante el último periodo del gobierno de Allende.

En el siguiente cuadro se sintetiza en una visión diacrónica intertextual las imágenes de textos escolares de historia analizadas. 


\begin{tabular}{|c|c|c|}
\hline \multicolumn{3}{|c|}{ Visión diacrónica intertextual de imágenes en textos escolares de historia } \\
\hline & Pre-Reforma Educacional de 1999 & $\begin{array}{r}\text { Post-Reforma Educacional de } \\
1999 \\
\end{array}$ \\
\hline $\begin{array}{l}\text { Representación } \\
\text { de la violencia }\end{array}$ & $\begin{array}{l}\text {-Dado (asociado implícitamente a la } \\
\text { extrema izquierda/movimiento } \\
\text { revolucionario latinoamericano, Cuba) } \\
\text {-Mayor prominencia visual } \\
\text {-Modalidad: blanco y negro. ---- } \\
\text { Credibilidad en el género y momento } \\
\text { histórico. } \\
\text {-Alta coincidencia de significados } \\
\text { intersemióticos. }\end{array}$ & $\begin{array}{l}\text {-Mediana prominencia } \\
\text {-Modalidad: blanco y negro/color. } \\
\text { Credibilidad en el género y } \\
\text { momento histórico. } \\
\text {-Recursos de atenuación de la } \\
\text { violencia. Reafirmación del mensaje } \\
\text { de reconciliación y consenso del } \\
\text { texto escrito. } \\
\text {-Baja coincidencia de significados } \\
\text { intersemióticos. }\end{array}$ \\
\hline $\begin{array}{l}\text { Representación } \\
\text { de A. Pinochet }\end{array}$ & $\begin{array}{l}\text {-Dado/ideal, asociado a la Junta } \\
\text { Militar (fotografía de los cuatro } \\
\text { integrantes). } \\
\text {-Imágenes conceptuales. } \\
\text {-Pinochet como líder y dictador. }\end{array}$ & $\begin{array}{l}\text {-Pinochet como líder y dictador. } \\
\text { Pinochet como presidente } \\
\text { constitucional. } \\
\text { - Imágenes conceptuales. } \\
\text {-Recursos de atenuación y } \\
\text { "blanqueo" de la figura dictatorial } \\
\text { de Pinochet. }\end{array}$ \\
\hline $\begin{array}{l}\text { Representación } \\
\text { del Palacio de } \\
\text { La Moneda }\end{array}$ & $\begin{array}{l}\text {-Modalidad alta/credibilidad. Imagen } \\
\text { nítida en blanco y negro. } \\
\text {-Imagen conceptual que transmite } \\
\text { tranquilidad y normalidad asociada al } \\
\text { inicio de la dictadura militar. }\end{array}$ & $\begin{array}{l}\text {-Composición variada, tendencia a } \\
\text { ubicarla en espacios de menor } \\
\text { prominencia a medida que pasa el } \\
\text { tiempo (excepto texto 2005-2006: } \\
\text { inicio de unidad). } \\
\text {-Modalidad alta/credibilidad: } \\
\text { imagen en blanco y negro, tonos } \\
\text { sepia. } \\
\text {-Imagen narrativa que se asocia al } \\
\text { término de la crisis del gobierno de } \\
\text { Allende. }\end{array}$ \\
\hline
\end{tabular}

\section{Algunas reflexiones finales}

La historia es una disciplina política e interpretativa, y por lo mismo, no podemos dejar de considerar que la representación de los eventos y los silencios son productos de una interpretación ideológica. Ellos responden a una construcción deliberada del pasado por quienes tienen el poder de legitimar sus lecturas. Las fotografías constituyen evidencias 'oficiales' del pasado al ser incorporadas en los textos escolares, así como la inclusión de las mismas imágenes en diferentes textos escolares van generando significados intertextuales que se construyen como saberes establecidos. Las imágenes son utilizadas para dar prominencia a los aspectos positivos o negativos que los grupos más poderosos desean reforzar, por ejemplo el 
"blanqueo" de la representación de A. Pinochet. Asimismo, las imágenes sirven como recurso atenuador de los aspectos negativos que se desean o no resaltar, por ejemplo: enfatizar el clima de violencia y atribuirlo exclusivamente a la extrema izquierda (1973), o atenuar el clima de violencia de los primeros años de la dictadura en los textos más recientes Post-Reforma Educacional. Los silencios en los textos escolares de historia no se producen únicamente en un nivel lingüístico, así como las imágenes y textos escritos no siempre están ideológicamente alineados en los textos escolares analizados. Las imágenes también nos hablan de los actores y eventos que son resaltados o silenciados, como Fidel Castro en textos Pre-Reforma Educacional y las violaciones a los derechos humanos en los textos Pre y Post Reforma Educacional. Las imágenes constituyen otro modo semiótico de construcción de explicaciones históricas que permite explorar diferentes posibilidades de significados produciendo, entre otros, los siguientes resultados: 1. Oposición ideológica entre textos e imágenes.2. Representación particular de actores sociales. 3. Refuerzo del status quo (política de consenso y reconciliación de los gobiernos de la transición democrática). 4. Entrega de información adicional. 5. Silenciamiento de los eventos que se desea tengan menos impacto y peso político o social en la sociedad (responsabilidad por los crímenes/ representación de minorías políticas) en un momento histórico determinado. Parece de suma importancia introducir a nuestros estudiantes a herramientas analíticas de la multimodalidad para que puedan comprender mejor las posibilidades de intersemiosis y el valor ideológico que porta cada modalidad.

E-mail: teresaoteiza@uach.cl

\section{REFERENCIAS}

Achugar, M. y M. Schleppegrell. 2005. Beyond connectors: The construction of cause in history textbooks. Linguistics and Education, 16: 298-318.

Bakhtin, M. \& M. Holquist. 1981. The dialogic imagination: four essays. Austin: University of Texas Press.

BALDRY, A. Ed..1999. Multimodality and Multimediality in the distance learning age. Campo Basso: Lampo.

Cofrin, C. 2002. The Voices of History: Theorizing the Interpersonal Semantics of Historical Discourses. Text, 22(4): 503-528. 
2006. Historical discourse: the language of time, cause and evaluation. London, New York: Continuum.

Crismore, A. 1984. The Rhetoric of Textbooks: Metadiscourse. Journal of Curriculum Studies, 16:279-96.

Halliday, M.A.K .1994. An Introduction to Functional Grammar. London: Edward Arnold.

Guo, L. 2004. Multimodality in a biology book. En: K. O'Halloran Ed.. Multimodal Discourse Analysis. Systemic Functional Perspectives. London/ New York: Continuum, pp. 196-219.

Kress, G. 2003. Literacy in the New Media Age. London/New York: Routledge KRESS, Gunther. 1996. Representational resources and the production of subjectivity: Questions for the theoretical development of Critical Discourse Analysis in a multicultural society. En: Carmen Rosa CaldasCoulthard y Malcolm Coulthard. Eds.. Texts and Practices. Readings in Critical Discourse Analysis. London: Routledge.

Kress, Gunther y Theo van Leeuwen. 1996. Reading Images. The Grammar of Visual Design. London/New York: Routledge.

Kress, Gunther y Theo van LeEuwen. 2001. Multimodal Discourse: the modes and media of contemporary communication. New York: Oxford University Press.

Kristeva, J. 1986. Word, dialogue and novel. En: T.Moi. Ed.. The Kristeva Reader. Oxford: Basil Blackwell.

Lemke, J. 1995. Textual politics: discourse and social dynamics. Londres: Taylor $\&$ Francis.

Lister, M. y L. Wells. 2001. Seeing beyonf belief: Cultural Studies as an approach to analyzing the visual. En: T. van Leeuwen y C. Jewit. Eds.. Handbook of Visual Analysis. Londres: Sage.

O'Halloran, K. Ed.. 2004. Multimodal Discourse Analysis. Systemic Functional Perspectives. London/New York: Continuum.

Oteíza, T. 2003. How Contemporary History is Presented in Chilean Middle School Textbooks. Discourse \& Society, 14(5): 639-660. . 2006. El discurso pedagógico de la historia. Un análisis lingüístico sobre la construcción ideológica de la historia de Chile (1970-2001). Santiago, Chile: Frasis editores.

.En prensa Revista Signos. Solidaridad ideológica en el discurso de la historia: tensión entre orientaciones monoglósicas y heteroglósicas.

Oteíza, T, y D. Pinto. 2008. Agency, Responsibility and Silence in the Construction of Contemporary History in Chile and Spain'. Discourse E Society, 19(3): 333-358. 
Pang Kah Meng, A. 2004. Making history in From Colony to Nation: a multimodal analysis of a museum exhibition in Singapore. En: K. O'Halloran. Ed.. Multimodal Discourse Analysis. Systemic FunctionalPerspectives. London/New York: Continuum, pp. 28-54.

Schleppegrell, M, Achugar, M. y Oteíza, T. 2004. The Grammar of History: Enhancing Content-Based Instruction through a Functional Focus on Language. Tesol Quarterly, 38: 67-93.

Trouillot Michael-Rolph. 1995. Silencing the past. Power and the Production of History. Boston: Beacon Press

van LeEuwen, Theo. 1996. The representation of social actors. En: C.R. Caldas-Coulthard y M. Coulthard. Eds.. Texts and Practices: Readings in Critical Discourse Analysis. London: Routledge.

\section{Textos escolares}

Almeyda, L, P. Milos y P. Wipple. 2005-06. Historia y Ciencias Sociales. Texto para el estudiante. Segundo Medio. Gobierno de Chile, Ministerio de Educación: Editorial Marenostrum.

Cembrano, Dina y Luz Eliana Cisternas. 1999. Estudio y Comprensión de la Sociedad._Ciencias Sociales. Sexto año básico, Santiago, Chile: Arrayán editores.

CheIx, Raúl y Jorge GutiérRez. 1986, 1993. Conociendo mi tierra y mi gente. Historia y Geografía de Chile. Cuarto año E. Media. Santiago, Chile: Editorial Salesiana.

Krebs, Andrea, Verónica Matte y Nelly Musalem. 1998. Historia y Geografía Octavo año básico, Santiago, Chile: Editorial Universitaria.

Matte, Verónica, Andrea Krebs, Eduardo Sepúlveda y Victoria Silva. 2000. Estudio y Comprensión de la Sociedad. Sexto año básico. Ministerio de Educación, Santiago-Chile. McGraw-Hill Interamericana.

Matte, Verónica y Andrea Krebs. 2001. Estudio y Comprensión de la Sociedad. Sexto año básico. Ministerio de Educación, Santiago-Chile. McGrawHill Interamericana.

Ministerio de Educación República de Chile. 1999. Programa de Estudio Sexto básico, Santiago, Chile: Ministerio de Educación.

Ministerio de Educación República de Chile. 1999. Programa de Estudio Segundo Año Medio, Santiago, Chile: Ministerio de Educación.

Rojas Leiva, Manuel José (ed.). 1998. Historia y Geografía, Octavo año básico, Santiago-Chile: Editorial Santillana.

VIAL, Gonzalo. 1994. Historia de Chile. Cuarto año medio. Santiago-Chile: Editorial Santillana. 